\title{
MÜLLER, Ronice de Quadros; CRUZ, Carina Rabello. Língua de sinais - instrumentos de avaliação. Porto Alegre: ARTMED, 2011. 159 p.
}

\author{
Por/ by Pedro Perini-Santos* \\ Pontifícia Universidade Católica de Minas Gerais - PUCMINAS \\ Universidade Federal de Minas Gerais - UFMG, Belo Horizonte, BR
}

Lingua de Sinais - instrumentos de avaliação - de Ronice Müller de Quadros (UFSC) e Carina Rabello Cruz (UFSC) - discorre sobre questões teóricas e práticas a respeito do ensino das línguas de sinais. O objetivo central do livro é a apresentação da metodologia e dos resultados de uma pesquisa sobre a aprendizagem de Libras, desenvolvida com surdos de aquisição precoce ou tardia. Sua leitura é rica para profissionais que atuam diretamente na área: professores, intérpretes, pedagogos, linguistas, fonoaudiólogos e tecnólogos em comunicação assistiva.

A obra se organiza em três capítulos. O primeiro descorre sobre o processo de aquisição da língua de sinais pela criança surda dentro de um enquadramento teórico gerativista. O segundo capítulo apresenta instrumentos de avaliação da língua de sinais desenvolvidos a partir de experimentos realizados pelas autoras no período entre 2002 e 2007 e os respectivos resultados. E o terceiro capítulo oferece um breve rol de técnicas de intervenção escolar no caso de lacunas na aprendizagem da língua de sinais. O livro é bom, instigante e bastante denso, especialmente quando expõe os dados do experimento final.

Discorrerei sobre os três capítulos do livro separadamente. Alguns comentários pessoais serão apresentados ao longo da resenha, com maior atenção dirigida para o processo de aquisição das línguas de sinais. Os comentários críticos que aqui sugiro são, sobretudo, de ordem conceitual. Parece-me haver algumas incongruências no livro Línguas de Sinais que mais se devem ao quadro teórico inicial escolhido do que à proposta descritiva do livro ela mesma.

A parte inicial do primeiro capítulo (Aquisição e Desenvolvimento da Linguagem na Criança Surda) é dedicada ao processo de aquisição de línguas de sinais. As autoras tomam como base o mesmo postulado que comumente é também apresentado para a aquisição das línguas orais. Propõem que, se a criança surda for exposta "a oportunidades naturais", essa será "capaz de atingir uma língua com todas as possibilidades que apresenta” (p. 31). Ou seja, a criança será plenamente hábil em língua de sinais, apesar de ser (supostamente) restrito o input por ela recebido. Esse argumento é conhecido como argumento da pobreza de estímulo linguístico e remete a um ponto central (e discutível, como veremos) da gramática gerativa apresentado por Noam Chomsky (1959; 1965), e endossado por vários autores. Apenas como ilustração, cito os trabalhos de Natalia Komarova: "as crianças adquirem a gramática mental de sua língua nativa rapidamente e sem educação formal [...] aos 3 anos de idade já efetivaram 90\% desse processo" (KOMAROVA et al., 2001, p. 43) e de Rodrigo Gonçalves (2007): "é exatamente esse argumento, chamado argumento da pobreza de estímulo, que corrobora a hipótese de que só uma teoria de bases inatas […] poderia dar conta adequadamente dos procedimentos de aquisição de linguagem" (GONÇALVES, 2007, p. 4).

Depois da apresentação dessa concepção de aquisição linguística, o livro traz um quadro sintético com as etapas de aquisição e desenvolvimento da linguagem comuns às crianças surdas e às ouvintes até os seis anos de idade. Entre o primeiro ano e o segundo ano de vida, "tanto crianças surdas quanto crianças ouvintes esticam os dois braços pedindo colo" (p. 19), associando movimentos corporais, gestos, expressões faciais, sons e sinalizações com fins específicos. (O que interessantemente muito se aproxima do conceito de joint attention de Tomasello (2003).).

Após os dois anos de idade, estabelecem-se diferenças entre os dois perfis de falantes. Com dois anos, as crianças surdas começam a fazer as primeiras combinações de sinalizações, associando com maior frequência as formas verbo/objeto e participante/objeto. Configuram-se com isso as primeiras construções sintáticas

\footnotetext{
*Email: pedro.perini.santos@gmail.com.
} 
em língua de sinais. Dessa etapa em diante, as crianças surdas passam por um período de "explosão do vocabulário, pois o bebê começa a falar sem parar" (p. 21). As autoras fazem referência à capacidade de reconhecer palavras, reconhecer processos, narrar eventos, fazer solicitações diversas, inferir e diferenciar as funções de verbo e de substantivo, como, por exemplo, diferenciar CADEIRA e SENTAR, que têm em comum a mesma configuração de mão. É também a partir dessa idade que começam a usar as formas pronominais. O uso dos pronomes e de outras formas de recuperação anafórica torna-as hábeis para introduzir "pontos no espaço não deixando dúvidas quanto a sua identidade, inclusive omitindo-os de forma adequada, possibilitando ao receptor recuperá-los” (p. 24).

Quadros e Cruz citam pesquisas feitas sobre aquisição de linguagem entre surdos que chegaram a resultados bastante divergentes. Fala-se na "independência da qualidade do input recebido pela criança" em relação à sua prática linguística: "o que parece determinar a aquisição da linguagem é o que está por trás da expressão linguística, ou seja, são os princípios que regem a aquisição da linguagem” (p. 31), aludindo-se à proposta inatista da gramática gerativa. No entanto, relatam mais adiante casos de crianças surdas que, por terem sido expostas tardiamente à língua sinalizada, desenvolveram "dificuldades em alguns tipos de construções" (p. 31) e ainda há "uma visível diferença no nível de desenvolvimento linguístico entre a trajetória da criança surda filha de pais ouvintes, e a da criança surda filha de pais surdos” (p.31).

Além disso, a nota de pé-de-página número 7 chama muito a atenção. Em movimento oposto às crianças ouvintes, as autoras relatam que no caso de famílias pais-ouvintes/filhos-surdos, que são a maioria, é a criança que "ensina no dia a dia a língua de sinais aos seus pais" (p. 30). Esse é um ponto muito interessante que merece, creio, ser investigado em pesquisas futuras.

A segunda parte do primeiro capítulo trata das críticas à proposta inatista. Para a teoria gerativa, o ser humano nasce dotado de um dispositivo biológico que o habilita a produzir um volume potencial de frases infinito a partir de uma experiência restrita com estímulos comunicativos externos. É possível ao ser humano gerar uma quantidade infinita de sentenças inéditas a partir do contato com poucos estímulos, se e somente se esse nascer com faculdades mentais aptas para tal realização. A forma usada por Chomsky para localizar fisicamente tal habilidade foi a expressão metafórica mental organ, ou seja, tudo se passa como se os seres humanos tivessem um 'órgão mental' capaz de efetivar a linguagem independentemente da quantidade de input recebido.

Em Radical Embodied Cognitive Science, Chemero (2009) analisa tal argumento da seguinte forma. A ideia de que as crianças (a) aprendam a falar rapidamente (b) a partir de experiências com input reduzido que leva à conclusão de ser (c) a gramática essencialmente inata não tem relações causais sustentáveis. Para as premissas (a) e (b). Chemero (2009) adverte que Chomsky não apresenta dados empíricos, mas apenas indicações intuitivas. Assim, (a) e (b) são premissas "semiempíricas". A quantité négligeable de estímulos e a rapidez de aprendizagem linguística não são fatos comprovados, mas são suposições. Logo, a conclusão expressa em (c) não é sustentável. Indicação disso encontra-se no fato de gerativistas reconhecidos passarem a considerar as variações de input como elemento relevante (ver JACKENDOFF, 2002; HAWKINS, 2004).

Se aplicada ao estudo sobre as línguas sinalizadas, a reflexão crítica de Chemero (2009) permite interpretações que, a meu ver, já aparecem no decorrer do livro. A ideia básica é a seguinte: toda e qualquer situação de interação comunicativa entre pais e filhos, entre os filhos entre si e entre os filhos e os colegas da escola são práticas determinadas pelas opções sociais dos envolvidos.

Mesmo que pareçam ser "naturais", e que pareçam ocorrer "naturalmente", as conversas entre adultos e crianças são construções sociais. Pesquisas indicam que a escolha da língua a ser falada em uma (micro)comunidade varia muito. Quando se vive em um grupo linguístico onde muitas línguas são usadas, o grau de amadurecimento de uma, de duas ou de várias línguas é fortemente condicionado por práticas sociais (HORNBERGER, 2002). Pode haver especialização, e consequente restrição de uso em função de motivação temática, emotiva, funcional, étnica, escolar etc. Na Índia, e em quase todos os países da África subsaariana, por exemplo, é notório o reconhecimento de que o uso da maior parte das línguas se restringe ao ambiente estritamente doméstico, fazendo com que a maior parte dessas línguas não atinjam sua forma expressiva plena (HARBERT, 2009). Por esse mesmo raciocínio, famílias bilíngues, usuárias de Libras e de português, tanto podem criar ambientes para o uso efetivo das duas línguas, quanto podem praticar uma forma funcional de Libras paralelamente ao uso de português pleno com os ouvintes da casa. A naturalidade do uso da língua de sinais depende da opção que a família fizer. Posto que em cerca de $90 \%$ dos casos as 
crianças surdas têm os pais ouvintes, a efetivação plena de uma dita linguagem natural é dependente de um contex to interativo complexo.

O que significa isso? Significa que a restrição de input e/ou que a "transmissão irregular" (termo que tomo emprestado à crioulística) da língua de sinais são aspectos influentes no amadurecimento das práticas comunicativas de uma criança surda.

Em estudo de acompanhamento escolar longitudinal realizado junto a crianças surdas na Holanda, nota-se a efetivação de melhores resultados escolares quando os pais dessas crianças são eles também usuários plenos da língua de sinais do país (SCHERMER, 2003). A opção por um modelo simplificado de língua de sinais, conclui Schermer (2003), interfere no amadurecimento cognitivo das crianças. Ainda dentro dessa linha: em pesquisa de caso realizada com pré-adolescente surdo de aquisição linguística tardia, Hyde et al. (2011) reconhecem proficiência na lida com operações simbólicas e geométricas básicas, legando-lhes forte razão intuitiva, mas registram deficiência em raciocínios geométricas combinatórios e de referência espacial, devida à falta de expressão linguística para tal.

O livro Língua de Sinais - instrumentos de avaliação fala sobre isso. Em vários momentos, as autoras explicitam quando falam sobre um grupo de crianças surdas, cujos pais são surdos, ou um grupo de crianças surdas, cujos pais não são surdos (páginas $13 ; 15 ; 24 ; 26 ; 47 ; 73$, dentre outras). De certa forma, o próprio livro relativiza a "naturalidade" da aquisição da língua de sinais, condicionando-a ao contacto direto entre interlocutores familiares. Assim, é natural a aquisição da Libras se as crianças surdas participarem de um ambiente de uso natural da Libras, sendo que esse ambiente natural só é possível se os pais, surdos ou não, forem usuários plenos da língua de sinais.

Levando mais adiante: não são apenas os pais que se relacionam comunicativamente com a criança surda, mas também os irmãos e os colegas de escola etc. Quadros e Cruz apontam para esse caminho. Após a constatação de "estarmos diante de muitas crianças surdas com atrasos na exposição à língua de sinais" (p. 88), realçam que "as aprendizagens devem ser funcionais no mundo social da criança; as situações familiares e escolares devem ser buscadas a fim de potencializar o uso da aprendizagem específica” (p. 88). Ou seja - e aqui retomo a crítica proposta por Chemero (2009) -, se o input não for pleno na família e na escola, pareceme possível que também não sejam plenos a aquisição, o desenvolvimento e o amadurecimento das línguas de sinais.

O Instrumento de Avaliação da Língua de Sinais (IALS), foco da explanação no capítulo 2, é o resultado de pesquisa empírica realizada entre 2002 e 2007. Inicialmente como projeto piloto, as estratégias de avaliação foram aperfeiçoadas e aplicadas a um grupo formado por 120 informantes. Os informantes foram divididos em dois grupos de usuários de Libras surdos: um primeiro de aquisição precoce (até 4:6 anos) e outro de aquisição tardia (após os 4:6 anos). A pesquisa avalia a expressividade e a compreensão de vocabulário, o uso de classificadores, o uso de referências, a narração de fatos em sequência lógica e a quantidade de fatos narrados (a partir de uma história apresentada como estímulo). O IALS tem três fases de complexidade progressiva: na fase I, são apresentadas frases com estrutura sintática simples; na fase II, as sentenças sinalizadas são mais longas e com vocabulário mais extenso; e na fase III, além de maior complexidade sintática e de vocabulário, também ocorrem sentenças encaixadas, coordenadas e relativas. Finalmente, em dois momentos distintos da pesquisa, almeja-se a constatação do (i) nível de compreensão (ou "linguagem compreensiva", nos termos das autoras) e (ii) do nível de produção dos informantes (ou "linguagem expressiva").

Dois fatores temporais são cruzados nos gráficos de resultados a partir da aplicação do IALS: (a) o fato de ser usuário precoce ou (b) usuário tardio de Libras e o Tempo de Exposição (TE) ao uso da Libras em uma escala de 4 a 9 anos. Como tendência geral, nota-se que, em todos os aspectos analisados, há melhor desempenho entre os usuários precoces.

Observações sobre linguagem compreensiva foram feitas apenas com crianças com aquisição precoce da Libras. Anuncia-se que a mesma pesquisa será feita com pessoas de aquisição tardia para fins comparativos. Os resultados são apresentados em tabelas de difícil compreensão (a notação da idade e do TE não está bem explicada), mas aponta-se para uma tendência clara: quanto maior o tempo de exposição à língua de sinais, melhor é o seu desempenho de compreensão. 
Os resultados referentes aos níveis de produção de Libras são graficamente apresentados em categorias compostas a partir do cruzamento dos critérios listados pelas autoras. Assim, os dados são expostos em matrizes como:

(a) [aquisição precoce; TE < 4; fase I; uso de classificadores: 16,7\% do previsto nos testes], ou seja, com um tempo de exposição à Libras inferior a 4 anos, crianças de aquisição precoce realizam 16,7\% dos itens previstos neste teste.

(b) [aquisição tardia; TE > 4 e < 7; fase III; vocabulário bom: 35,7\% do previsto nos testes], ou seja, com um tempo de exposição à Libras entre 4 e 7 anos, crianças de aquisição tardia realizam 35,7\% dos itens previstos neste teste.

Ao todo são dezoito tabelas. Dez tabelas contêm os dados relativos aos quesitos examinados e as outras oito tabelas apresentam dispositivos comparativos com a evolução de desempenho relativamente ao TE. Como tendências gerais, têm melhor desempenho os falantes precoces e os falantes expostos a um tempo maior de uso de exposição, sendo que esses fatores se associam, ou seja, se precoces e com TE mais longo, melhor desempenho.

No capítulo 3, são apresentadas vinte práticas interventivas de produção e compreensão em Libras a partir de imagens, jogos, vídeos e relatos narrativos: sete visam prioritariamente o desenvolvimento do vocabulário; três buscam amadurecer as configurações de mão; oito desenvolvem a sintaxe; e dois tem um carácter mais textual e dialógico. O que é proposto se aproxima de uma didática comunicativa para o ensino de L2, ma troppo infantile. O livro não expressa a qual faixa etária se destinam as técnicas de intervenção, mas nitidamente percebe-se que melhor se adequariam a crianças bem novas, e contam como certa a participação criativa constante dos alunos; o que me parece pouco provável. As atividades são muito centradas nelas mesmas e não na conjugação com práticas posteriores derivadas da estimulação visual ou verbal. Não há também uma contextualização temática ou tensional, no sentido do desafio narrativo, sugerida previamente ao começo das intervenções. (Ressalva: não deve ser nada fácil criar práticas de intervenção neste contexto dialógico.)

Lingua de Sinais - instrumentos de avaliação suscita bons debates acerca da aquisição e do desenvolvimento das habilidades em Libras e, por conseguinte, nas línguas de sinais como categoria tipológica. O livro abre um importante caminho de pesquisa que pede a aplicação dos mesmos procedimentos em outros grupos para verificação das tendências observadas. Creio também que coleta empírica semelhante pode ser novamente aplicada, mas com maior detalhamento dos metadados. Com isso, talvez se possa ter mais clareza sobre o peso das práticas comunicativas cotidianas dos informantes. Vale considerar se usam Libras (i) os dois pais ou apenas um; (ii) os irmãos ou apenas um; (iii) se na escola ou no trabalho há outras pessoas surdas ou ouvintes usuárias de Libras; (iv) se os ouvintes que usam Libras a conhecem com destreza; e (v) se os surdos fazem universidade. Creio que são elementos a serem considerados em pesquisas futuras; o que felizmente aparece anunciado como projeto das autoras.

\section{REFERÊNCIAS}

CHEMERO, Anthony. Radical embodied cognitive science. Massachussetes: MIT Press, 2009.

CHOMSKY, Noam. A review of B. F. Skinner's verbal behavior aspects. Language, v. 35, n. 1, p. 26-58, 1959.

Aspects of theory of syntax. Cambridge: MIT Press, 1965.

GONÇALVES, Rodrigo. Chomsky e o aspecto criativo da linguagem. Revista virtual de estudos da linguagem, V. 5, n. 8, 2007.

HARBERT, Wayne (Ed.). Language and poverty. Toronto: Multilingual Matters, 2009.

HAWKINS, John. Efficiency and complexity in grammars. Oxford: Oxford University Press, 2004.

HYDE, Daniel; et al. Spatial and numerical abilities without a complete natural language. Neuropsychologia, v. 49, p. 924-936, 2011. 
HORNBERGER, Nancy. Multilingual language policies and the continua of biliteracy: an ecological approach. Language policy, v. 1, p. 27-51, 2002.

JACKENDOFF, Ray. Foundations of language. Oxford: Oxford University Press, 2002.

KOMAROVA, Natalia; NIYGI, Partha; NOVAK, Martin. The evolutionary dynamics of grammar acquisition. Journal of theoretical biology, v. 209, p. 43-59, 2001

SCHERMER, Trude. From variant to standard: an overview of the standardization process of the lexicon of sign language of the Netherlands over two decades. Sign language studies, v. 3, n. 4, p. 469-486, 2003.

TOMASELLO, Michael. Constructing a language. Cambridge: Harvard University Press, 2003.

Recebido em 22/03/12. Aprovado em 05/06/12. 